\title{
Mi identidad nikkei
}

Recibido: $19 / 02 / 2020$

Aprobado: 20/05/2020

Publicado: 25/08/2020

Ana María Higa

Universidad Nacional Mayor de San Marcos <amhigay@gmail.com>

\section{RESUMEN}

Se revisa el concepto nikkei en el contexto socio-cultural peruano y el peso de la cultura japonesa para explorar el itinerario seguido por sus ancestros migrantes de la isla de Okinawa. Usando los propios recuerdos y algunas conversaciones familiares, reconstruye el tránsito de sus padres y abuelos del valle de Huaral (Chancay) a la ciudad de Lima-Callao. Luego su retorno siendo ella infante, ofrece una información simple sobre su vida en la escuela local, sus estudios en Lima en las etapas de secundaria y la universidad, etapas en las que asimila su identidad nikkei y el proceso de interacción laboral sin perder su fortaleza y cultura japonesa.

Palabras clave: Nikkei, ancestros, migrantes, memorias, convivencia.

\section{My own nikkei identity}

\begin{abstract}
The Nikkei concept is reviewed within the peruvian sociocultural context, by her own life experience, to explore her origin from her grandparents, who came from Okinawa Island as a migrants, by the early 20th century, she make the building memories by herself, about her parents, and her life experience in transit from Huaral, Callao and Lima. Some singular figure of her life is offered, since the early childhood, school age, go through to the university and the professional interaction, when she understood the value to have and maintain her own Nikkei identity within the japanesse culture, in convivence to the Peruvian culture .
\end{abstract}

KEYworDs: Nikkei, ancestrus, migrants, memories, convivence 
D eseo agradecer al profesor Humberto Rodríguez Pastor, por la deferencia de compartir mi experiencia de vida y hacer que me haya detenido unos momentos en reencontrarme y aceptar mi identidad nikkei en convivencia con la identidad peruana a la que formalmente pertenecemos.

Para iniciar mi historia considero necesario acudir a ciertas definiciones que permitan un mejor entendimiento del significado "Nikkei".

\section{¿Qué es ser nikkei?}

Según la Asociación Peruano Japonesa, el término nikkeidefinea todasaquellas personasdescendientes de japoneses, incluyendo a los de ascendencia mixta, es decir aquellos que tienen origen japonés por línea materna o paterna. Menciona también que, para la escritora nikkei Doris Moromisato, es «toda persona de ascendencia japonesa que reside fuera de Japón y forma parte de una comunidad y de un estilo de vida con características propias». Agrega que también se les denomina «mestizos de otras razas».

La Asociación asume en su definición los conceptos vertidos por José Watanabe, Amelia Morimoto y Martín Chambi, autores del libro La memoria del ojo: "Los primeros hijos de los inmigrantes escucharon en sus años infantiles que algún día toda la familia se iría al Japón, aquel país solo conocido de oídas. No se fueron y la cultura paterna y del entorno crearon un nuevo grupo de mestizos en el Perú: los nisei, luego vinieron otras generaciones, ahora todas conocidas como nikkei»; ellos dicen también que "no interesa el estereotipo, no importa que tengan rasgos asiáticos. ¡Cuántas veces les habrán gritado ‘chinoı!, en cualquier lugar de Lima o del Perú. Saben que detrás de esas «máscaras», los nikkei saben que su identidad es peruana, más allá de los rasgos físicos, en las generaciones más recientes los elementos de la cultura japonesa suelen aparecer como particularidades, las más de las veces subjetivas", y que es parte del proceso de mestizaje cultural. Su identidad central es la peruana.

En este contexto, que me parece familiar, procedo a compartir mi propia experiencia de vida personal, que me ha permitido reflexionar a profundidad sobre mi propia identidad.

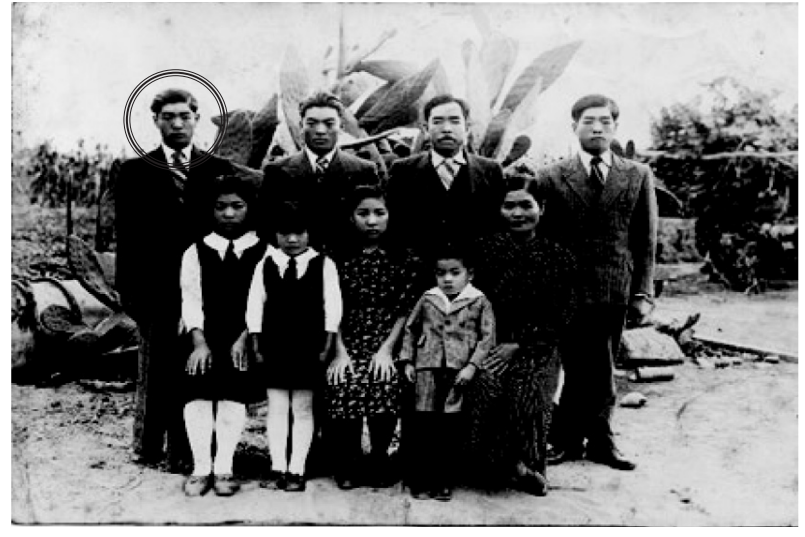

Familia Higa: los abuelos, mi padre y hermanos.

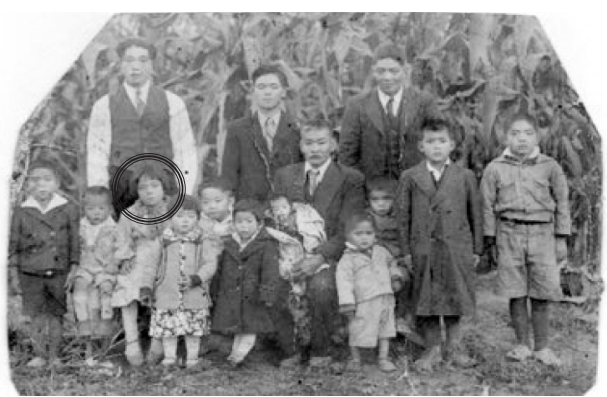

Familia Yamashiro: mi madre, niña. Cuando vivían en el campo.

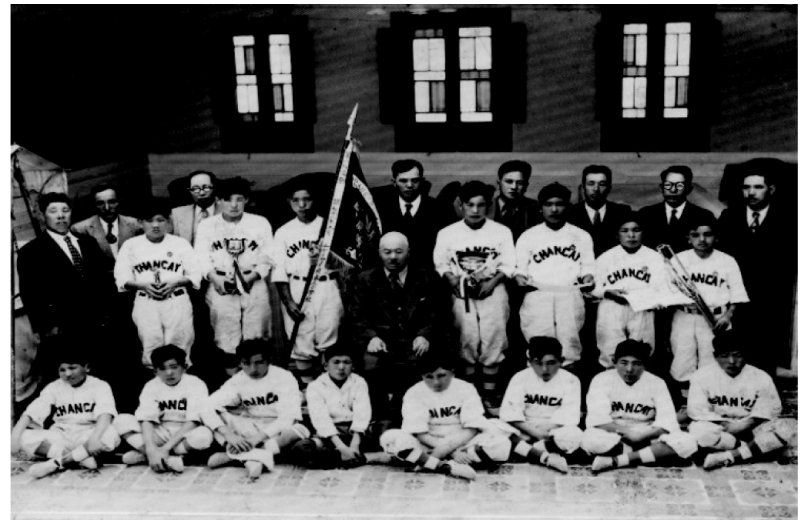

Selección de béisbol del colegio Chancay Nikko a la que perteneció mi padre.

\section{Mis orígenes}

Hacia el año 1920, mis abuelos (Ollichan, Obachan) Eicho Higa y su esposa Kame, por lado paterno y Kame Yamashiro y su esposa Koshiro (lado materno), emprendieron un largo camino a la tierra prometida Perú. Pero según conto mi madre, ellos se desilusionaron al ver la cruda realidad, que no había condiciones para tener una vida digna y supongo que tuvieron que acogerse a ser peones de las haciendas, 
dedicándose a labores agrícolas. Ellos se instalaron en una zona eriaza, en Huaral, donde empezaron su vida familiar y tuvieron siete hijos, tres mujeres y cuatro varones. Mi ollichan Yamashiro a su vez tuvo cinco hijos cuatro varones y mi madre la única mujer. Uno de los aspectos que he lamentado mucho, ha sido tener como barrera la lengua materna, lo que no me permitió tener una relación directa con ninguno de los abuelos, ellos eran procedentes de la isla de Okinawa donde se habla el dialecto nativo (uchinauchi), y mis padres solo nos hablaban en español. Lo poco que supimos de los inicios de la migración de mis abuelos en Perú, fue a través de nuestros padres.

Ellos, mis padres, aún eran nińos cuando fueron afectados muy seriamente con los estragos de la Segunda Guerra Mundial, cuando se les cerró las escuelas japonesas y se les prohibió hablar japonés, con lo cual se nos privó de esta primera oportunidad de comunicación fluida con nuestros abuelos.

Según nos contó mi madre estaban en el colegio, mi papá en sexto grado y mi mami en tercero, cuando irrumpió la guerra y dado que Perú apoyó a Estados Unidos, el gobierno hizo cerrar las escuelas japonesas. A partir de allí se inicia una etapa de sufrimiento y explotación de todos los japoneses a quienes confiscaron sus tierras y los convirtieron en peones de las haciendas. Cuando éramos pequeños mi madre nos contaba cosas que no entendíamos, nos decía que los varones fueron a las chacras y las niñas como ella debían ayudar a algunas de las mamás que eran asignadas para preparar la olla común, el rancho, como lo conocían ellos. No tengo claro esta etapa en que mis abuelos migran del campo a la ciudad, y las dos familias se mudaron al Callao. La familia Higa adquirió un edificio frente al Mercado Central de Lima que tenía en el primer piso una cafetería, en ese tiempo le decían lechería, donde vendían desayuno en la mañana y luego lo mismo en la tarde. Y mi abuelo Yamashiro se estableció por la Av. Argentina donde adquirieron una panadería.

\section{Mi familia}

Mis padres se casaron en el Callao y allí nacimos mi hermano y hermana mayores y yo. Por cosas del destino, un tío paterno le dio a mi padre el encargo de administrar sus tierras en la hacienda Esquivel, valle

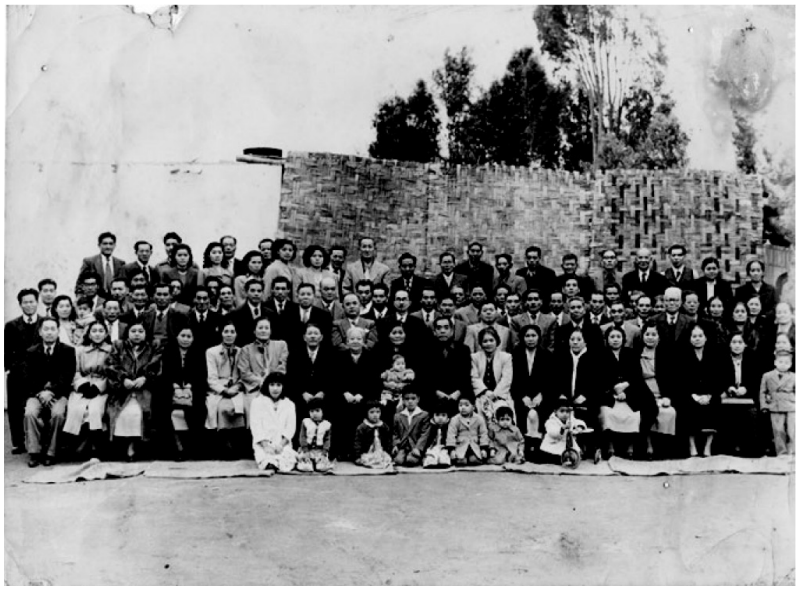

Comunidad japonesa en los años 50 en que regresamos a Huaral, a modo de despedida de los tíos de mi padre que volvían a Japón.

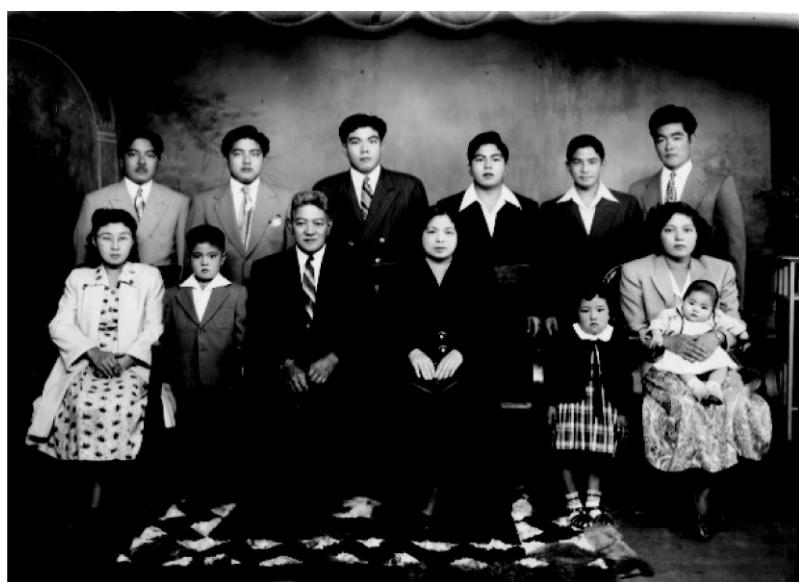

Mis padres, hermanos y yo, con la familia Yamashiro, abuelos maternos. Foto de archivo familiar.

de Huaral, y cuando el tío decidió regresar a Japón, le entregó ese terreno: así emprendimos la aventura de vivir en el campo. En ese momento yo tenía tres meses, era abril de 1952. Pude conseguir una fotografía que muestra la formalidad de la colonia japonesa cuando se despidió a los tíos de mi padre.

Durante mis primeros ańos el círculo social de mis padres era solo familias japonesas hasta que se inició la vida escolar de mi hermano mayor en el distrito de Huaral.

Cada año nuevo existía la tradición de reunirse todas las familias de cada zona de donde eran oriundos los abuelos, los Higa, del sonjin Urasoe y los Yamashiro de Itoman, y se realizaban actividades de confraternidad.

Luego de la posguerra, se conformó la Asociación Peruano Japonesa del valle de Huaral-Chancay. De 
lo que recuerdo, mi padre tuvo en ello una participación activa, y se concretó la construcción de una sede institucional en la ciudad de Huaral, actualmente forma parte de un local de reuniones, una cancha deportiva, un centro educativo y un policlínico, cuya implementación se realizó principalmente mediante donaciones del gobierno de Japón. Actualmente se brinda atención a la población general del valle de Huaral-Chancay siendo esto un aporte importante a la sociedad huaralina. Se ha dado así un paso más a la integración.

Durante mis primeros años de infancia el círculo social de mis padres estaba conformado solo por familias japonesas hasta que se inició la vida escolar de mi hermano mayor en el distrito de Huaral. Aprendí mucho de las prácticas agrícolas y también de la crianza de aves, disfrutando en grande de la vida de campo. Nuestra casa constituyó un espacio importante de reunión familiar y también de espacio de visitas de parientes japoneses y algunas autoridades locales de las zonas de origen de mis padres (Urasoe) que visitaron el país en las décadas de los 80 .

\section{Mi vida escolar y universitaria}

Es en esta etapa en la que fui apreciando diferencias en algunas costumbres y prácticas. Como vivíamos en el campo, mi padre gestionó una pensión de almuerzo en casa de la directora de la escuela y para mí fue un primer contacto con las culinaria criolla peruana, aun cuando en casa de mi madre ya preparaban algunos de esas viandas criollas. La directora de la escuela La Inmaculada pertenecía a una familia huaralina que conservaba el modelo tradicional de familia peruana. A nivel escolar, fui observando por un lado que en los salones donde había descendientes nikkeis era común que ocupáramos los primeros lugares en rendimiento académico, así como en el cumplimiento de tareas. Por el lado social, fui aprendiendo en esa interacción familiar con la familia Aparicio, propietaria del colegio, dado que al momento del almuerzo tuvimos la suerte de ser incorporados en la mesa familiar. Allí aprendimos a comer la comida criolla.

En la secundaria, tuve una situación particular de separarme de la familia, debido a la oportunidad de estudiar en la modalidad de internado mediante una beca escolar otorgada por el Ministerio de

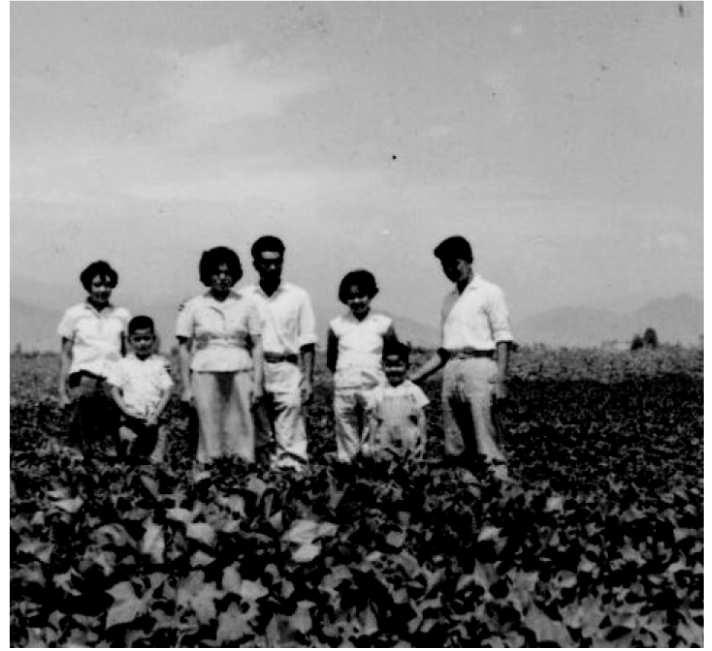

Mi familia en el campo, 1964. Foto de archivo familiar.

Educación en la Gran Unidad Escolar Miguel Grau de Magdalena del Mar. Y allí se fue consolidando de cierta forma la identidad nikkei, en la cual aprecié ciertas particularidades como ser más reservada, o en general la cualidad de ser más estudiosos y también que era esperado que alguien de la colonia japonesa y china fueran los alumnos más destacados a nivel de toda la unidad escolar.

Tuve como compañeras de internado a Olga, una niña nikkei, una niña nacida en China y nacionalizada peruana y otra joven tusán cuyo padre era chino y madre peruana, todas ellas muy estudiosas y siempre ocupaban los primeros lugares en rendimiento escolar. Y nuestra tendencia era a juntarnos por sentir más afinidad, para el grupo de compañeras todas éramos "chinas", ellas no distinguían chino de japonés. En cierta forma sentía cierta "discriminación positiva" no solo de las compañeras sino también de las profesoras, yo sentía que ellas esperaban de nosotras un alto rendimiento, expectativa que afortunadamente pudimos mostrar.

En la universidad me he sentido en mi identidad peruana, pero de vez en cuando algunos comentarios de los compañeros me devolvían a mi identidad japonesa, igual se manejaba el apelativo de "china".

\section{Mi entorno laboral y social}

En mi profesión, mi entorno laboral y el social me fue dando señales que las personas con las que interactuaba, tenían la expectativa de identificar en mi 


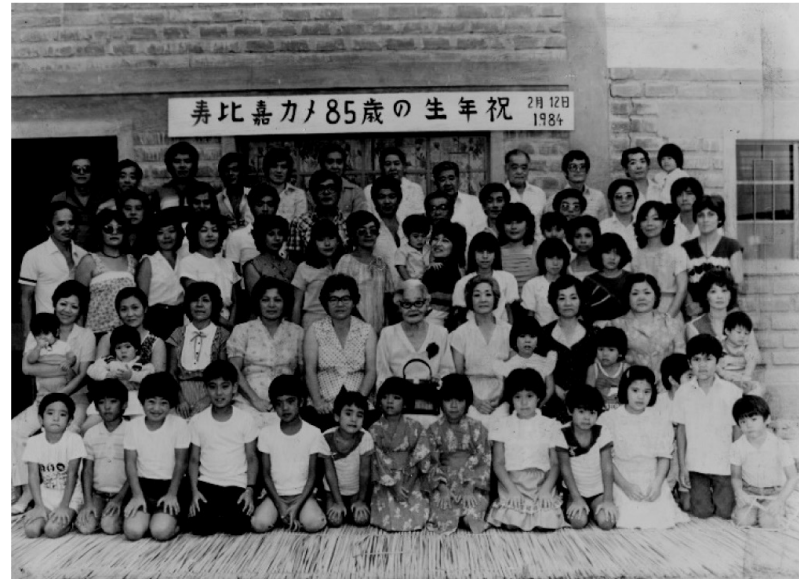

Mi familia paterna cuando la abuela cumplió 85 años, rodeada de hijos y nietos. Celebración importante para la colonia japonesa, 1986.

algunas tradiciones japonesas. Es lo que sentí en mis primeras experiencias de trabajo profesional, desde el Ministerio de Salud, cuando desarrollaba un programa de capacitación en Nutrición a docentes de primaria a nivel nacional, realizados en las sedes de educación departamentales, los participantes tenían interés de saber si yo mantenía las costumbres de mis padres. Igual era la interacción con el personal de salud cuando realizaba las capacitaciones o visitas de supervisión regulares a las provincias, o salíamos al campo en provincias, las familias tenían muchas expectativas sobre mi persona y preguntaban siempre si había nacido en Japón, o si mantenía las costumbres japonesas. Un aspecto importante de mencionar es que fui identificando ciertas similitudes en el comportamiento andino y lo japonés, sobre todo en el área rural, como el sentimiento colectivo, la búsqueda de bienestar de la comunidad en su conjunto.

Otro aspecto que puedo mencionar, la cosmovisión andina que se maneja desde la influencia de la luna y que yo observaba y escuchaba a mi padre cuando leía el calendario lunar para los períodos de siembra, por ejemplo. Lamento no haber tomado atención en esos momentos sobre la riqueza de esos conocimientos y las implicancias culturales que marcan a los grupos.

Un tema que constituye quizás la influencia más importante de la migración es la fusión de la gastronomía peruana y japonesa y del cual disfrutamos mucho como nikkeis, pero se conserva aún parte de la tradición con preparaciones específicas para ciertas ceremonias de celebraciones o de duelo.

Mi profesión me enseñó a apreciar el valor de la cultura y el respeto a la diversidad cultural y en particular en mi situación de nieta de migrantes japoneses, poder conservar la mía. En el aspecto alimentario se percibe el posicionamiento social que nos alcanza también con la comida nikkei, y que Amelia Morimoto lo describe en su artículo sobre cocina peruana.

En lo personal, al ser docente de Nutrición, mi identidad nikkei me ha permitido conjugar el valor de dos culturas alimentarias distintas y que puedo compartir directamente con nuestros estudiantes, abriendo su comprensión a otras miradas y las cuales han podido recrear otro escenario de diversidad como la comida fusión nikkei.

El escribir esta nota me ha generado curiosidad por revisar y leer a quienes han escrito algo relacionado a la identidad nikkei y pienso que han identificado muy acertadamente nuestras características socioculturales. Un tema que me gusta conservar y trato de explorar más es sobre el calendario oriental cuyo ciclo es de 12 años, simbolizado en 12 animales que según la leyenda contada por mi madre, fueron llamados por Buda.

En verdad pienso que cada ciclo de 12 años se puede relacionar con cada etapa de la vida: niñez, adolescencia, juventud adultez y senectud en la que se practica ciertos ritos y costumbres celebratorias.

Me he permitido una interpretación personal, muy empírica por cierto, pero con cierta lógica de sus significados. Por ejemplo, en el primer año de vida, proyectar sus preferencias, y prever condiciones para que el nińo/niña pueda desarrollar plenamente sus capacidades y celebraciones particulares cada 12 años, y para la mujer joven a los 19 ańos, por lo menos en la cultura okinawense, en el adulto varón que a los 40 se espera llegue a su desarrollo personal y familiar, a los 60 años tanto el hombre como la mujer llegan a una etapa de su vida que empieza a acumular sabiduría.

Y que se celebra con mayor algarabía, etapa en la que mi madre me decía, se vuelve a condiciones de la nińez a partir de los 85 años, donde nuestros ancianos merecen toda la dedicación y respeto por su sabiduría. 


\section{Conclusión}

Ahora, ya como adulta mayor, siento que las raíces nuevamente se fortalecen y la generación de mis hijos y mis nietos continúan aprendiendo de la cultura japonesa. Se ha vuelto a considerar nombres peruanojaponeses con los nietos, con lo cual pienso se dará continuidad a la identidad nikkei por esta generación.

Mi propia percepción es que mi identidad aglutina sentimientos de peruanidad pero con un sello personalizado por la cultura japonesa, que ahora hemos adquirido un estatus como nikkei en la sociedad peruana, y así lo expresé también en la última encuesta de INEI, me asigné la categoría étnica de nikkei. Particularmente, lo siento como una discriminación positiva en términos de ser considerados perseverantes, trabajadores, disciplinados, y en términos negativos para la idiosincrasia peruana, nuestra parquedad en la comunicación verbal.

Y tomo textualmente de la Asociación Peruano Japonesa:

Pero, ¿cómo ven los estudiosos peruanos a los descendientes de japoneses? Según el sociólogo Gonzalo Portocarrero, en una entrevista publicada en la revista Caretas, «los nikkei son un grupo con una gran movilidad social», es decir resalta su laboriosidad que se acriolló. Se refiere a que son personas muy trabajadoras que surgieron de etapas y situaciones difíciles.

De la apreciación que hace Portocarrero de laboriosidad, en lo personal, tengo una anécdota: cuando asumí la Dirección de un Programa Nacional en el MINSA y trabajamos sin horario, un distinguido profesor de la Facultad, que ya nos dejó, me dijo: «la felicito, jovencita, aunque en la administración pública no es para tanto, pero a usted se le perdona que trabaje mucho porque es japonesa».
Bonfiglio (1997), en su reseña sobre el libro Hacia un nuevo sol de Mery Fukumoto, resalta que la autora revela en dicha publicación que «la integración de los inmigrantes japoneses en la sociedad peruana ha sido un proceso efectivo, que se ha revitalizado dado que sus descendientes son peruanos y ellos se sienten peruanos distintos al resto pero peruanos al fin».

Finalmente, una situación que a veces nos generaba cierta desazón, de sentir que aquí en Perú somos vistos como japoneses, pero allá, en Japón, para ellos somos extranjeros, y no iguales a los japoneses; como menciona Tessa Morris-Susuki, hay una cierta línea de sentimientos encontrados, pero que el haber sido capaces de construir la identidad nikkei nos hace sentir con una identidad propia en la que somos reconocidos aquí y en Japón por igual como nikkei. Luego soy NIKKEI y siento orgullo de serlo.

\section{Referencias}

Bonfiglio, G. (1997). Fukumoto, Mary, 1997. Hacia un nuevo sol. Japoneses y sus descendientes en el Perú: historia, cultura e identidad, Lima: Asociación Peruano Japonesa del Perú, 602 pp. Apuntes. Revista de Ciencias Sociales, (40), 133-135. https://doi.org/https://doi. org/10.21678/apuntes.40.459

JaRrod GrabHam, Ethnic_Fusion_The_emergence_of_ the_Perúvian_Nikkei_identity_in_Lima. https://www. academia.edu/12710570/. Acceso, noviembre 2019.

Morris-Suzuki, T. (2010). Borderline Japan: foreigners and frontier controls in the postwar era / Tessa MorrisSuzuki Cambridge University Press Cambridge; New York, 2010, p. 241. Citado por Jarrod Grabham.

Proyecto Discover Nikkei (2009-2010). Lima-Perú, Abril 2010/Amelia Morimoto, editora y coordinado http://www.discovernikkei.org/es/journal/2010/4/27/ cocina-peruana/ acceso 19/07/2020.

https:// www. apj.org.pe/que-es-ser-nikkei 